Article

\title{
Towards Water Soluble Mitochondria-Targeting Theranostic Osmium(II) Triazole-Based Complexes
}

\author{
Salem A. E. Omar ${ }^{1}$, Paul A. Scattergood ${ }^{1}$, Luke K. McKenzie ${ }^{2,3}$, Helen E. Bryant ${ }^{3}$, \\ Julia A. Weinstein ${ }^{2}$ and Paul I. P. Elliott ${ }^{1, *}$ \\ 1 Department of Chemistry, University of Huddersfield, Queensgate, Huddersfield HD1 3DH, UK; \\ Salem.Omar@hud.ac.uk (S.A.E.O.); P.Scattergood@hud.ac.uk (P.A.S.) \\ 2 Department of Chemistry, Dainton Building, University of Sheffield, Sheffield S3 7HF, UK; \\ lkmckenzie1@sheffield.ac.uk (L.K.M.); julia.weinstein@sheffield.ac.uk (J.A.W.) \\ 3 Academic Unit of Molecular Oncology, Sheffield Institute for Nucleic Acids (SInFoNiA), \\ Department of Oncology and Metabolism, University of Sheffield, Beech Hill Road, Sheffield S10 2RX, UK; \\ h.bryant@sheffield.ac.uk \\ * Correspondence: p.i.elliott@hud.ac.uk; Tel.: +44-1484-472320 \\ Academic Editor: James Crowley \\ Received: 29 September 2016; Accepted: 12 October 2016; Published: 18 October 2016
}

\begin{abstract}
The complex $\left[\mathrm{Os}(\text { btzpy })_{2}\right]\left[\mathrm{PF}_{6}\right]_{2}$ (1, btzpy = 2,6-bis(1-phenyl-1,2,3-triazol-4-yl)pyridine) has been prepared and characterised. Complex 1 exhibits phosphorescence $\left(\lambda_{\text {em }}=595 \mathrm{~nm}, \tau=937 \mathrm{~ns}\right.$, $\phi_{\mathrm{em}}=9.3 \%$ in degassed acetonitrile) in contrast to its known ruthenium(II) analogue, which is non-emissive at room temperature. The complex undergoes significant oxygen-dependent quenching of emission with a 43-fold reduction in luminescence intensity between degassed and aerated acetonitrile solutions, indicating its potential to act as a singlet oxygen sensitiser. Complex $\mathbf{1}$ underwent counterion metathesis to yield $\left[\mathrm{Os}(\text { btzpy })_{2}\right] \mathrm{Cl}_{2}\left(\mathbf{1}^{\mathrm{Cl}}\right)$, which shows near identical optical absorption and emission spectra to those of $\mathbf{1}$. Direct measurement of the yield of singlet oxygen sensitised by $1^{\mathrm{Cl}}$ was carried out $\left(\phi\left({ }^{1} \mathrm{O}_{2}\right)=57 \%\right)$ for air equilibrated acetonitrile solutions. On the basis of these photophysical properties, preliminary cellular uptake and luminescence microscopy imaging studies were conducted. Complex $\mathbf{1}^{\mathrm{Cl}}$ readily entered the cancer cell lines HeLa and U2OS with mitochondrial staining seen and intense emission allowing for imaging at concentrations as low as $1 \mu \mathrm{M}$. Long-term toxicity results indicate low toxicity in HeLa cells with LD50 >100 $\mu$ M. Osmium(II) complexes based on 1 therefore present an excellent platform for the development of novel theranostic agents for anticancer activity.
\end{abstract}

Keywords: triazole; osmium; photophysics; complexes; ligands; anticancer; oxygen sensitizer

\section{Introduction}

Oligopyridyl complexes of kinetically inert $\mathrm{d}^{6}$ metals, e.g., $\mathrm{Ru}(\mathrm{II}), \mathrm{Os}(\mathrm{II})$, have attracted enormous interest in recent decades due to their attractive photophysical properties [1-4]. These complexes typically exhibit relatively long-lived triplet metal-to-ligand charge transfer ( ${ }^{3}$ MLCT) states. These states may undergo deactivation through a number of routes including phosphorescence or energy/electron transfer which enables the potential application of these complexes in light-emitting [5] and photovoltaic technologies [6]. Key to the development of complexes for these applications is the design of the ligands supporting these metals. We, and others, have paid particular attention to the use of copper-catalysed coupling of alkynes and azides to form 1,2,3-triazole-based ligands [7-10] and have investigated the photophysical properties of their resultant complexes. A significant number of reports have appeared detailing the photophysical and photochemical properties of triazole-based complexes of $\operatorname{Re}(\mathrm{I}), \mathrm{Ru}(\mathrm{II})$ and $\mathrm{Ir}(\mathrm{III})$ [11-25]. Examples of triazole-containing complexes of osmium(II) 
are, however, comparatively rare. We have recently reported the synthesis and characterization of deep-red/near-IR emissive osmium(II) bitriazolyl (btz) complexes and demonstrated their use in light-emitting electrochemical cells [19].

Of recent and growing interest has been the use of luminescent complexes in biological applications [26-28]. Since phosphorescence is longer-lived than the autofluorescence from biological organic compounds, emissive complexes are amenable to use in time-gated imaging microscopy [29-31]. Osmium(II) complexes, however, often exhibit lower energy spin-forbidden direct ${ }^{3}$ MLCT optical absorption bands of moderate extinction coefficient due to the high spin-orbit coupling constant for the osmium centre [32,33]. This offers the advantage of enabling efficient excitation at lower energies that therefore avoids potential cellular damage and negates autofluorescence and the necessity of the added expense of time-gated apparatus. These absorption and emission bands at wavelengths closer to the red in comparison to those of common iridium(III) complexes, and therefore in a more biologically transparent region of the spectrum, will also enable greater depth of penetration for excitation and imaging. Complexes of osmium(II) are also typically highly inert to ligand photosubstitution making them highly robust [34] (although the unprecedentedly facile ligand photoejection in the complex $\left[\mathrm{Os}(\mathrm{btz})_{3}\right]^{2+}$ was recently reported [35]). The intensity of phosphorescence is, however, sensitive to the presence of oxygen resulting in quenching through conversion of ground state ${ }^{3} \mathrm{O}_{2}$ to reactive ${ }^{1} \mathrm{O}_{2}$, thus enabling exploitation in photodynamic therapy (PDT) [36]. These combined properties thus present significant opportunities for the development of unique dual-mode theranostic agents.

We report here the synthesis and characterization of the orange-emissive bis(terdentate) osmium(II) complex [Os(btzpy) $\left.{ }_{2}\right]^{2+}$ (btzpy $=2,6$-bis(1-phenyl-1,2,3-triazol-4-yl)pyridine) as its hexafluorophosphate $(\mathbf{1})$ and chloride $\left(\mathbf{1}^{\mathrm{Cl}}\right)$ salts. The complex shows significant dependence of emission intensity on the presence of oxygen. The water soluble chloride salt $\mathbf{1}^{\mathrm{Cl}}$ has been subjected to preliminary cellular uptake and luminescence imaging studies and relevant results are reported.

\section{Results \& Discussion}

Complex 1 was prepared by reaction of two equivalents of the ligand btzpy $[37,38]$ with $\left[\mathrm{OsCl}_{6}\right]\left[\mathrm{NH}_{4}\right]_{2}$ in refluxing ethylene glycol (Scheme 1). After being left to cool, the complex was isolated as an orange powder, its hexafluorophosphate salt, through treatment with $\mathrm{NH}_{4} \mathrm{PF}_{6}$. The ${ }^{1} \mathrm{H}-\mathrm{NMR}$ spectrum of $\mathbf{1}$ exhibits a characteristic singlet resonance for four equivalent triazole ring protons at $\delta 9.13$, which is deshielded relative to the corresponding signal for the free ligand by $0.16 \mathrm{ppm}$. The protons of the central pyridine ring give rise to doublet and triplet resonances at $\delta 8.36$ and 8.01 , respectively, with those for the phenyl substituents resulting in multiplets between $\delta 7.50$ and 7.60. For spectroscopic comparison the complex $\left[\mathrm{Os}(\text { tolterpy })_{2}\right]\left[\mathrm{PF}_{6}\right]_{2}$ $\left(2\right.$, tolterpy $=4^{\prime}-p$-tolyl-2, $2^{\prime}: 6^{\prime}, 2^{\prime \prime}$-terpyridine $)$ was also prepared.
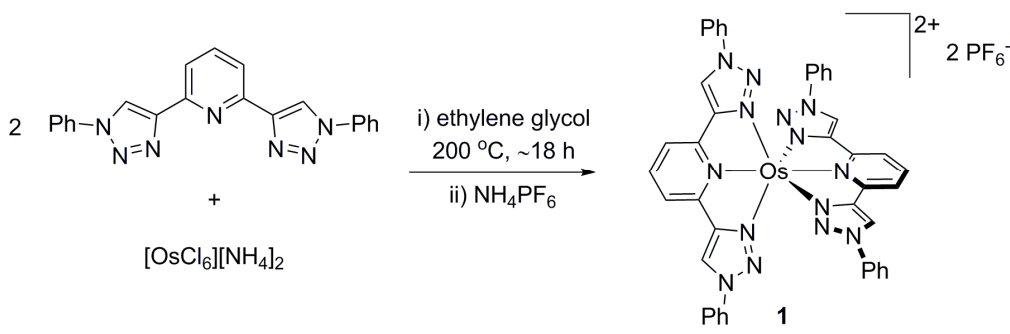

Scheme 1. Synthesis of $\left[\mathrm{Os}(\text { btzpy })_{2}\right]\left[\mathrm{PF}_{6}\right]_{2}(\mathbf{1})$.

The electrochemical properties of $\mathbf{1}$ were investigated by cyclic voltammetry (CV) and reveal a reversible $\mathrm{Os}(\mathrm{II}) / \mathrm{Os}(\mathrm{III})$ oxidation at $+0.64 \mathrm{~V}$ ( $\mathrm{vs} \mathrm{Fc} / \mathrm{Fc}^{+}=0.0 \mathrm{~V}$ ). This is close to that exhibited by the known model complex $2\left(\mathrm{E}^{\mathrm{ox}}=+0.49 \mathrm{~V}\right)$ and other related osmium(II) complexes [39-41] indicating that the highest occupied molecular orbital (HOMO) has primarily metallic $5 \mathrm{~d}$ orbital 
character. Unlike in the CV trace for 2, no ligand-based reductions are observed for $\mathbf{1}$ within the available electrochemical window $(-2.0$ to $+1.2 \mathrm{~V})$, which is indicative of the higher energy lowest unoccupied molecular orbital (LUMO) localized on the btzpy ligand compared to that for the tolterpy complex. This LUMO destabilisation is consistent with previously reported data on the ruthenium(II) analogue of 1 versus [Ru(terpy) 2$]^{2+}$ (terpy $=2,2^{\prime}: 6^{\prime}, 2^{\prime \prime}$-terpyridine) [42-44].

UV-visible absorption spectra were recorded for $\mathbf{1}$ and $\mathbf{2}$ in acetonitrile solutions at room temperature (Figure 1a and Table 1). The spectrum of 1 exhibits a strong absorption at $297 \mathrm{~nm}$ assigned to ligand-centred $\pi \rightarrow \pi^{*}$ transitions localized on the btzpy ligand along with a broad band between 350 and $400 \mathrm{~nm}$ assigned to ${ }^{1} \mathrm{MLCT}$ transitions. This is significantly blue-shifted relative to that observed for $2(491 \mathrm{~nm})$ consistent with the btzpy ligand, and hence its complex, having a much higher energy LUMO as indicated from the CV data described above. Similarly to the data for 2, complex 1 also exhibits absorptions of lesser intensity at longer wavelengths corresponding to spin-forbidden direct ${ }^{3}$ MLCT excitations $\left(\lambda^{\max }=526 \mathrm{~nm}\right)$ from the singlet ground state enabled by the large spin-orbit coupling constant associated with the osmium centre [32,33].

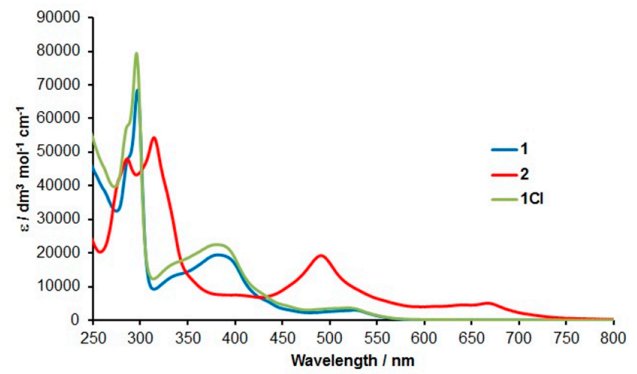

(a)

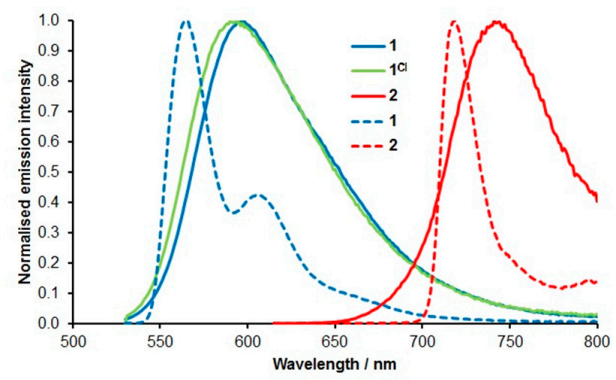

(b)

Figure 1. (a) UV-visible absorption spectra for 1 and 2 in acetonitrile solutions and $\mathbf{1}^{\mathrm{Cl}}$ in aqueous solution at room temperature; (b) normalized emission spectra of complexes $\mathbf{1}$ and $\mathbf{2}$ in de-aerated acetonitrile solutions and $\mathbf{1}^{\mathrm{Cl}}$ in aerated aqueous solution at room temperature (solid lines) and complexes 1 and 2 in 4:1 EtOH/MeOH glasses at $77 \mathrm{~K}$ (dashed lines).

Table 1. Summarised photophysical data for $1, \mathbf{1}^{\mathrm{Cl}}$ and 2 in acetonitrile.

\begin{tabular}{|c|c|c|c|c|c|}
\hline Complex & 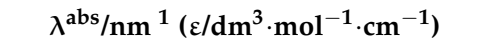 & $\lambda^{\mathrm{em} / \mathrm{nm}^{1}}$ & $\tau / \mathrm{ns}^{2,3}$ & $\phi_{\mathrm{em}} / \%{ }^{2,4}$ & $\lambda^{\mathrm{em} / \mathrm{nm}}{ }^{5}$ \\
\hline 1 & $\begin{array}{c}526(3025), 434(5700), 382(19,500) \\
337(13,500), 297(68,500), 288(49,000)\end{array}$ & $595^{6}$ & $937 \pm 12$ & 9.3 & $564,606^{6}$ \\
\hline${ }_{1}^{\mathrm{Cl}}$ & $\begin{array}{c}534(3315), 438(5800), 390(24,750), \\
345(17,350), 297(90,800), 287(62,500)\end{array}$ & $\begin{array}{c}599^{6} \\
(589)^{6,8}\end{array}$ & $\begin{array}{c}884 \pm 6 \\
(273 \pm 3)^{8}\end{array}$ & $\begin{array}{c}9.7(5.4) \\
8\end{array}$ & - \\
\hline 2 & $\begin{array}{c}669(5070), 645(4600), 491(1930), 406 \\
(7520), 314(54,300), 286(48,000)\end{array}$ & $738^{7}$ & $339 \pm 4$ & 3.2 & $718,795^{7}$ \\
\hline
\end{tabular}
${ }^{1} \mathrm{RT}$, acetonitrile solutions; ${ }^{2}$ Degassed MeCN at RT; ${ }^{3} \lambda^{\mathrm{ex}}=405 \mathrm{~nm} ;{ }^{4}$ Relative to $\left[\mathrm{Ru}(\mathrm{bpy})_{3}\right]\left[\mathrm{PF}_{6}\right]_{2} \phi_{\mathrm{em}}=0.018$ in
aerated MeCN [45]; ${ }^{5} 77 \mathrm{~K}, 4: 1 \mathrm{EtOH} / \mathrm{MeOH}$ glass; $;{ }^{6} \lambda^{\mathrm{ex}}=500 \mathrm{~nm} ;{ }^{7} \lambda^{\mathrm{ex}}=600 \mathrm{~nm} ;{ }^{8}$ Aerated aqueous solution.

In stark contrast to its ruthenium(II) analogue, $\mathbf{1}$ is emissive at room temperature in de-aerated acetonitrile solutions, with the emission being characterized by a broad featureless band at $595 \mathrm{~nm}$ $\left(\lambda^{\text {ex }}=500 \mathrm{~nm}\right)$ and a lifetime of $937 \mathrm{~ns}$ (Figure $1 \mathrm{~b}$ and Table 1 ) attributed to an emissive ${ }^{3}$ MLCT state. Bis(tridentate) complexes of ruthenium(II) typically show little or no emission at room temperature as the deviation from an ideal octahedral-like coordination geometry results in stabilization of triplet metal-centred $\left({ }^{3} \mathrm{MC}\right)$ states relative to the ${ }^{3} \mathrm{MLCT}$ state $[46,47]$. As such, ${ }^{3} \mathrm{MC}$ states are efficiently populated from photoexcited ${ }^{3} \mathrm{MLCT}$ states thereby quenching emission. The observed emission for 1 must therefore arise from the destabilization of the ${ }^{3} \mathrm{MC}$ states due to the typically larger ligand-field splitting associated with the $5 \mathrm{~d}$ metal centre over its $4 \mathrm{~d}$ counterpart, such that non-radiative depopulation of the emissive ${ }^{3}$ MLCT state is comparatively disfavoured. Mirroring the UV-visible 
absorption data, the emission spectra of $\mathbf{1}$ are significantly blue-shifted relative to those of $\mathbf{2}$ by $143 \mathrm{~nm}$ $\left(3260 \mathrm{~cm}^{-1}\right)$ indicative of the comparatively destabilized LUMO for 1, and hence also its ${ }^{3}$ MLCT state. The emission spectrum was also recorded at $77 \mathrm{~K}$ in a $4: 1 \mathrm{EtOH} / \mathrm{MeOH}$ glass matrix and shows a structured emission band that is blue-shifted relative to the spectrum at room temperature due to rigidochromic effects.

Emission intensity from $\mathbf{1}$ is dramatically affected by the presence of oxygen (Figure 2) and is quenched by approximately 43-fold when recorded in air compared to deaerated conditions. The long lifetime of emission combined with the oxygen sensitivity confirms the assignment of a ${ }^{3}$ MLCT-based emissive state. This significant quenching of emission by oxygen thus presents the possibility of utilizing complexes based on $\mathbf{1}$ as potential ${ }^{1} \mathrm{O}_{2}$ sensitizers for photodynamic therapeutic applications.
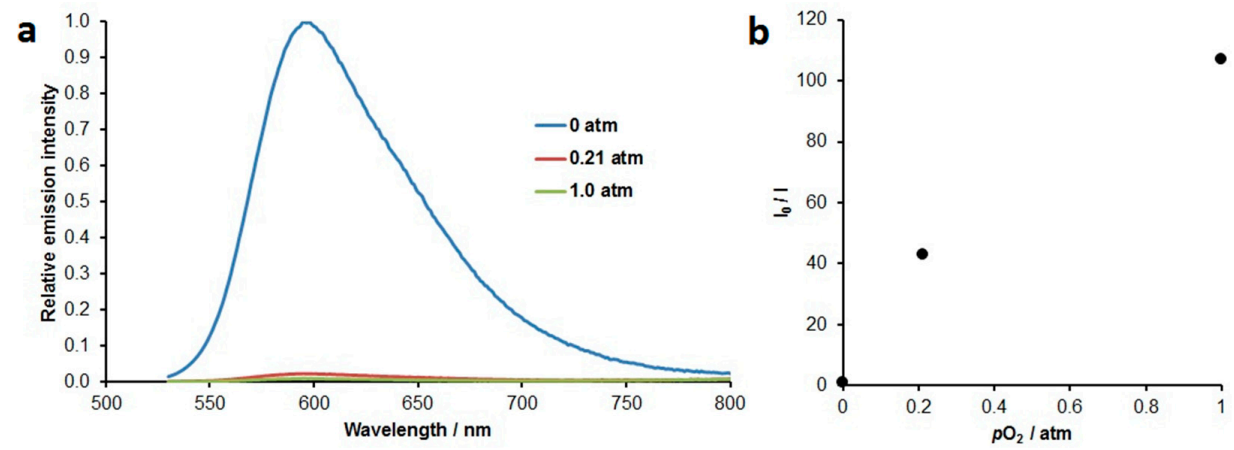

Figure 2. (a) Relative oxygen dependent emission spectra for 1 in acetonitrile (normalized for deoxygenated (vacuum) conditions) and (b) Stern-Volmer plot ( $I_{0}$ and $I$ are the emission intensities at $\lambda_{\max }$ for the degassed solution and solution at the partial pressure of oxygen at which emission is measured respectively).

Complex 1 was also studied by density functional theory (DFT) calculations to confirm the nature, localisation and relative energies of the frontier orbitals as well as to simulate the optical absorption spectrum. The data reveal that the HOMO is localized primarily on the osmium(II) centre as expected (Figure $3 a$ ) but with a small contribution from the $\pi$-systems of the four triazole rings. The LUMO is localized on one of the btzpy ligands, predominantly on the central pyridine ring and with a lesser contribution from the triazole rings (Figure $3 b$ ) but also a metallic d-orbital contribution. The HOMO of $\mathbf{1}$ is slightly stabilized $(-10.63 \mathrm{eV})$ relative to that of $\mathbf{2}(-10.35 \mathrm{eV})$ in agreement with the experimental electrochemical data. The LUMO $(-6.95 \mathrm{eV})$ on the other hand is significantly destabilized relative to that of $2(-7.32 \mathrm{eV})$ due to the smaller $\pi$-system associated with the btzpy ligand compare to tolterpy and due to the electron rich triazole moieties. This results in a larger HOMO-LUMO gap for $\mathbf{1}$ of $3.68 \mathrm{eV}$ compared to that for $\mathbf{2}(3.03 \mathrm{eV})$ mirroring the significantly blue-shifted absorption and emission data.
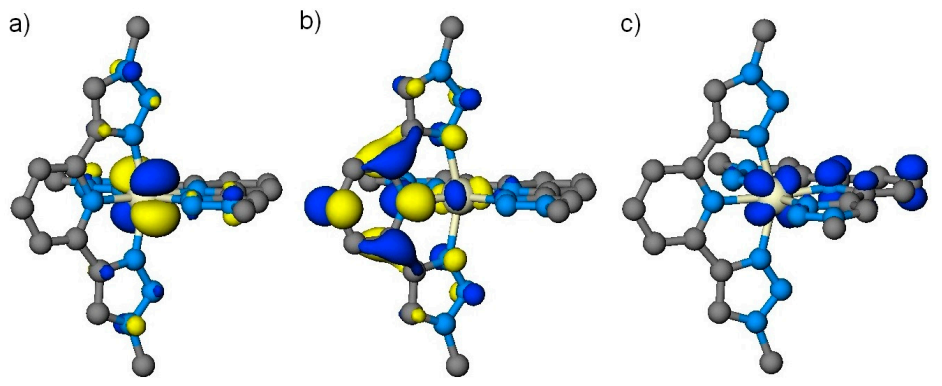

Figure 3. Plots of the $\mathrm{HOMO}(\mathbf{a})$ and LUMO (b) for the ground state of $\mathbf{1}$ and the spin density for the $\mathrm{T}_{1}$ state of $\mathbf{1}(\mathbf{c})$. 
Time-dependent DFT was used to calculate the lowest energy 30 singlet state vertical excitations at the ground state geometry along with the lowest energy 10 spin-forbidden triplet excitations for 1. The data agree well with the experimental spectra (Supporting Information) but with a slight overestimation of the energies of transitions compared to bands in the UV-visible absorption spectrum. The $S_{1}$ state is calculated to have an energy of $2.74 \mathrm{eV}(452 \mathrm{~nm})$ and is primarily $\mathrm{HOMO}$ $\rightarrow$ LUMO ${ }^{1} \mathrm{MLCT}$ in character. The first major transition $\left(\mathrm{S}_{7}, 374 \mathrm{~nm}\right)$ is predominantly composed of a $\mathrm{HOMO} \rightarrow \mathrm{LUMO}+2$ transition and is similarly of ${ }^{1} \mathrm{MLCT}$ character confirming our experimental assignment of the band in this region of the UV-visible absorption spectrum. The $\mathrm{T}_{1}$ transition is calculated to be at $512 \mathrm{~nm}(2.42 \mathrm{eV})$, is of mixed HOMO-2 $\rightarrow$ LUMO+1 and HOMO- $\rightarrow$ LUMO character and is therefore in agreement with the assignment of the lesser intensity absorptions between 450 and $550 \mathrm{~nm}$ as arising from spin-forbidden direct ${ }^{3}$ MLCT transitions.

The lowest lying triplet state of $\mathbf{1}$ was optimized starting from the optimized ground state geometry and is calculated to lie $2.40 \mathrm{eV}$ above the energy of the ground state. The spin density was plotted and is presented in Figure 3c. It reveals unpaired electron density on both the metal and one of the btzpy ligands confirming the ${ }^{3}$ MLCT character of this $\mathrm{T}_{1}$ state. Curiously, unlike in the case of $\mathbf{2}$, the $\mathrm{T}_{1}$ state of $\mathbf{1}$ undergoes a puckering like distortion of the btzpy ligand on which the unpaired electron density is localized. Such distortions have been observed, however, in theoretical calculations of the $\mathrm{T}_{1}$ states of bis(tridentate) ruthenium(II) cyclometalated complexes [48] and [Os(terpy) $]_{2}^{2+}[49$ ].

Conversion to the chloride salt, $\left[\mathrm{Os}(\text { btzpy })_{2}\right] \mathrm{Cl}_{2}\left(\mathbf{1}^{\mathrm{Cl}}\right)$, was achieved by stirring a suspension of 1 in methanol with Amberlite IRA-400 ion-exchange resin (chloride form) before filtering, removal of solvent and freeze-drying from aqueous solution. Removal of the hexafluorophosphate couterion was confirmed by the lack of the corresponding resonances in the ${ }^{19} \mathrm{~F}$ - and ${ }^{31} \mathrm{P}-\mathrm{NMR}$ spectra. The UV-visible absorption spectrum of $\mathbf{1}^{\mathrm{Cl}}$ (Figure 1) in aqueous solution is near identical to that of its analogous hexafluorophosphate salt $\mathbf{1}$ in acetonitrile. The complex is also emissive in aerated aqueous solution with an emission maximum at $589 \mathrm{~nm}$, very slightly blue-shifted relative to that of $\mathbf{1}$ in acetonitrile.

Based on the highly encouraging photophysical data reported above we decided to carry out preliminary studies on cell uptake and toxicity. Complex $\mathbf{1}^{\mathrm{Cl}}$ was seen to localise to the mitochondria in the cancer cell lines HeLa (cervical cancer) and U2OS (osteosarcoma) following a short incubation time of $4 \mathrm{~h}$ and with clear phosphorescence seen at concentrations as low as $1 \mu \mathrm{M}$. Colocalisation with the mitochondrial stain MitoView 633 was seen under confocal microscopy (Figure 4), giving Pearson's correlation coefficients of $\mathrm{r}=0.85$ and 0.7 for HeLa and U2OS cells respectively. A Pearson's correlation coefficient of 1 indicates complete concurrence of the stains, while 0 indicates no concurrence hence these values indicate that complex $1^{\mathrm{Cl}}$ preferentially localises to the mitochondria.

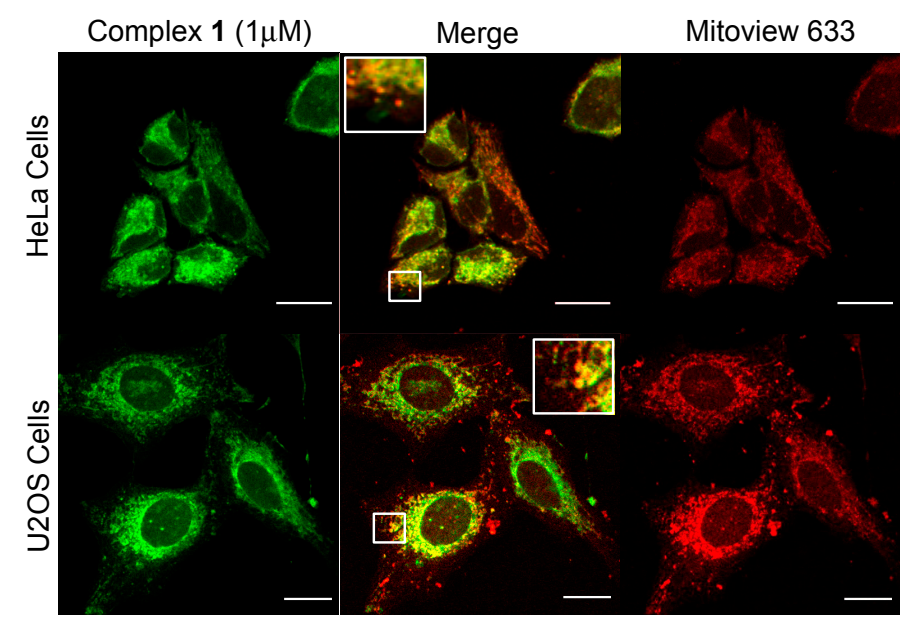

Figure 4. Confocal images of complex $\mathbf{1}^{\mathrm{Cl}}$ (green) following $4 \mathrm{~h}$ incubation in HeLa and U2OS cells co-localised with Mitoview 633 (red) with central overlaid image, scale bars $20 \mu \mathrm{m}$. 
The cellular viability of HeLa cells following incubation with complex $\mathbf{1}^{\mathrm{Cl}}$ at concentrations up to $100 \mu \mathrm{M}$ was assessed by MTT assay (Figure 5). In addition, long-term survival was assessed using clonogenic assays and indicated an $\mathrm{LD}_{50}>100 \mu \mathrm{M}$ in dark conditions. This shows that at a concentration effective for luminescence imaging microscopy the complex is non-cytotoxic, lending support to potential use as a PDT agent where non-toxicity in the dark is desired.
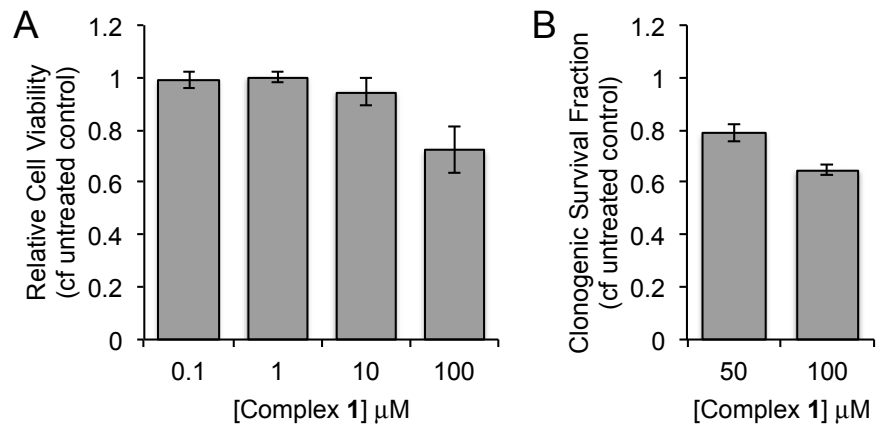

Figure 5. (A) MTT and (B) Clonogenic survival assays following incubation of HeLa cells with increasing concentrations of complex $1^{\mathrm{Cl}}$ in the dark. In each case, mean and standard deviation of at least 3 independent repeats is shown.

The yield of singlet oxygen generation, $\phi\left({ }^{1} \mathrm{O}_{2}\right)$, of complex $\mathbf{1}^{\mathrm{Cl}}$ was measured in air-equilibrated acetonitrile against the standard perinaphthenone. A $\phi\left({ }^{1} \mathrm{O}_{2}\right)$ of $57 \%$ was determined by direct measurement of the ${ }^{1} \Delta_{\mathrm{g}}$ state emission from ${ }^{1} \mathrm{O}_{2}$ in the NIR $\left(\lambda_{\mathrm{em}} 1275 \mathrm{~nm}\right)$ under $355 \mathrm{~nm}$ irradiation by a pulsed Nd:YAG laser as described previously [50]. It is proposed that apoptotic cell death after light treatment is associated with localisation of photosensitizers to mitochondria [51]. Thus the sub-cellular localisation, long-term survival following treatment of cancer cells with complex $\mathbf{1}^{\mathrm{Cl}}$ in the dark and the high singlet oxygen yield of $57 \%$ indicate the potential for this complex as a photosensitizer for PDT theranostic applications. We recognize that the wavelengths of absorption for $\mathbf{1}^{\mathrm{Cl}}$ are at relatively high energy compared to the ideal for a PDT agent and thus are not at the optimum position for maximum tissue penetration for excitation. However, modification of the basic design of the complex by making the ligand more electron-withdrawing, for example, should be a relatively easy task. Stabilisation of the LUMO, thus decreasing the HOMO-LUMO gap, would shift the electronic absorption of the complexes into the desired lower energy region of the spectrum. Based on these encouraging results, work is currently underway to fully determine the anticancer activity of $\mathbf{1}^{\mathrm{Cl}}$ and for the further development of $\mathbf{1}^{\mathrm{Cl}}$ and analogues thereof as a new class of potential PDT agents.

\section{Conclusions}

We have reported the synthesis, characterisation and photophysical properties of a novel luminescent osmium(II) triazole-based complex. The complex has been shown to exhibit significant quenching of luminescence intensity in the presence of oxygen and a high quantum yield for singlet oxygen sensitization as its chloride salt, indicating potential applications in photodynamic therapy as well as luminescence imaging microscopy. The water soluble chloride form of the complex was subjected to preliminary cellular uptake and luminescence imaging microscopy studies. The results from these studies reveal that the complex is successfully taken up by two cancer cell lines with mitochondrial localization and low dark toxicity.

The use of CuAAC coupling in ligand synthesis opens up diverse avenues for tailored derivitisation and bioconjugation that would enable the optimisation of cellular uptake and a wider scope for organelle targeting within cells. Combined with the attractive photophysical properties, the complex described in this contribution represents a highly versatile platform for the development of dual-mode luminescence imaging/singlet oxygen sensitisation photodynamic theranostic complexes. 
Plans to pursue these studies are in progress and results from these studies will be published elsewhere in due course.

\section{Experimental Section}

\subsection{General Methods}

Ammonium hexachloroosmate(IV) was purchased from Alfa Aesar (Ward Hill, MA, USA) whilst all other reagents were purchased from Sigma-Aldrich (Saint Louis, MO, USA), Acros Organics (Thermo Fisher Scientific, Geel, Belgium) or Fluorochem (Hadfield, UK) and used as supplied. The ligand btzpy [37] and complex 2 [52] were prepared by literature procedures. NMR spectra were recorded on a Bruker Ascend $400 \mathrm{MHz}$ spectrometer (Billerica, MA, USA), with all chemical shifts being quoted in ppm referenced relative to the residual solvent signal $\left(\mathrm{MeCN},{ }^{1} \mathrm{H}: \delta=1.94,{ }^{13} \mathrm{C}: 1.32\right.$, 118.26; DMSO, ${ }^{1} \mathrm{H}: \delta=2.50,{ }^{13} \mathrm{C}: 39.52$ ). High-resolution mass spectrometry was performed on an Agilent 6210 TOF instrument (Santa Clara, CA, USA) with a dual ESI source. UV-visible absorption spectra were recorded on an Agilent Cary 60 spectrophotometer whilst emission spectra were recorded on a Fluoromax 4 spectrophotometer (aerated and degassed in acetonitrile and data at $77 \mathrm{~K}$ in a 4:1 EtOH/MeOH glass). Lifetime measurements were performed using an Edinburgh instruments Mini-Tau spectrometer (Edinburgh, UK). Emission quantum yields $\left(\phi_{\mathrm{em}}\right)$ were measured for degassed MeCN solutions, with degassing carried out via three repeat freeze-pump-thaw cycles. Quantum yields are quoted relative to $\left[\mathrm{Ru}(\mathrm{bpy})_{3}\right]\left[\mathrm{PF}_{6}\right]_{2}$ in aerated $\mathrm{MeCN}$, with analyte solutions being excited at a single wavelength at a point of common optical density. Thus, $\phi_{\mathrm{em}}$ values are determined from the ratio of integrated area under the corrected peaks, with an assumed experimental uncertainty of $\pm 20 \%$. Cyclic voltammograms were recorded using an Autolab PGSTAT100N potentiostat with NOVA electrochemical software (version 1.10.1.9). Analyte solutions were prepared using nitrogen saturated dry acetonitrile, freshly distilled from $\mathrm{CaH}_{2}$. All measurements were conducted at room temperature under a stream of dry nitrogen at potential scan rates ranging from 20 to $500 \mathrm{mV} \cdot \mathrm{s}^{-1}$. $\left[\mathrm{NBu}_{4}\right]\left[\mathrm{PF}_{6}\right]$ was used as a supporting electrolyte, being recrystallised from ethanol and oven dried prior to use, with a typical solution concentration of $0.2 \mathrm{~mol} \mathrm{dm}^{-3}$. The working electrode was a platinum disc, with platinum wire utilised as the counter electrode. The reference electrode was $\mathrm{Ag} / \mathrm{AgCl}, \mathrm{being}$ chemically isolated from the analyte solution by an electrolyte containing bridge tube tipped with a porous frit. Ferrocene was employed as an internal reference, with all potentials quoted relative to the $\mathrm{Fc}^{+} / \mathrm{Fc}$ couple

\subsection{Synthesis of $\left[\mathrm{Os}(b t z p y)_{2}\right]\left[P F_{6}\right]_{2}(\mathbf{1})$}

Ammonium hexachloroosmate(IV) ([( $\left.\left.\left.\mathrm{NH}_{4}\right)_{2} \mathrm{OsCl}_{6}\right], 150 \mathrm{mg}, 0.341 \mathrm{mmol}\right)$ and 2.5 equivalents of 2,6-bis(1-phenyl-1H-1,2,3-triazol-4-yl)pyridine $(310 \mathrm{mg}, 0.85 \mathrm{mmol})$ in ethylene glycol $\left(25 \mathrm{~cm}^{3}\right) \mathrm{was}^{2}$ heated at reflux overnight under nitrogen. The resulting mixture was then allowed to cool to room temperature. 2.5 equivalents of aqueous $\mathrm{NH}_{4} \mathrm{PF}_{6}$ was added resulting in a dark brown precipitate which was collected by filtration and washed with cold water and diethyl ether. This was then redissolved in acetonitrile, cooled in the fridge overnight and filtered to remove unreacted ligand. The solvent was removed from the filtrate and the residue recrystallized from dichloromethane/hexane to give an orange powder. Yield $=185 \mathrm{mg}, 45 \% ;{ }^{1} \mathrm{H}-\mathrm{NMR}\left(400 \mathrm{MHz}, \mathrm{CD}_{3} \mathrm{CN}\right): \delta 9.13(\mathrm{~s}, 4 \mathrm{H}) ; 8.36$ $(\mathrm{d}, J=8.0 \mathrm{~Hz}, 4 \mathrm{H}) ; 8.01(\mathrm{t}, J=8.0 \mathrm{~Hz}, 2 \mathrm{H}) ; 7.49-7.60(\mathrm{~m}, 20 \mathrm{H}) .{ }^{13} \mathrm{C}-\mathrm{NMR}\left(101 \mathrm{MHz}, \mathrm{CD}_{3} \mathrm{CN}\right): \delta 153.26$, $151.74,138.26,136.94,131.12,131.07,124.98,121.64,120.18$. ESI HRMS: calculated for $\left[\mathrm{C}_{42} \mathrm{H}_{30} \mathrm{~N}_{14} \mathrm{Os}\right]^{2+}$ $m / z=461.1191 ;$ found $m / z=461.1195$.

\subsection{Synthesis of $\left[\mathrm{Os}(\text { btzpy })_{2}\right] \mathrm{Cl}_{2}\left(\mathbf{1}^{\mathrm{Cl}}\right)$}

A suspension of $\mathbf{1}(100 \mathrm{mg}, 0.083 \mathrm{mmol})$ in methanol $\left(25 \mathrm{~cm}^{3}\right)$ was stirred with Amberlite IRA-400 ion-exchange resin (chloride form, $200 \mathrm{mg}$ ) for $24 \mathrm{~h}$ at R.T. in the dark. The resin was removed by filtration and the solvent then removed by evaporation. The residue was then dissolved in water and 
the solution was freeze dried to yield $\mathbf{1}^{\mathrm{Cl}}$ as an orange powder. Yield $=71 \mathrm{mg}, 87 \%{ }^{1} \mathrm{H}-\mathrm{NMR}(400 \mathrm{MHz}$, $d_{6}$-DMSO): $\delta 10.15(\mathrm{~s}, 4 \mathrm{H}) ; 8.58(\mathrm{~d}, J=8.0 \mathrm{~Hz}, 4 \mathrm{H}) ; 8.21(\mathrm{t}, J=8.0 \mathrm{~Hz}, 2 \mathrm{H}) ; 7.66-7.72(\mathrm{~m}, 8 \mathrm{H}) ; 7.47-7.57$ (m, 12H). ${ }^{13} \mathrm{C}-\mathrm{NMR}\left(101 \mathrm{MHz}, d_{6}\right.$-DMSO): $\delta$ 152.01, 150.32, 137.57, 135.58, 130.08, 130.00, 125.27, 120.46, 119.31. ESI HRMS: calculated for $\left[\mathrm{C}_{42} \mathrm{H}_{30} \mathrm{~N}_{14} \mathrm{Os}\right]^{2+} \mathrm{m} / z=461.1191$; found $\mathrm{m} / z=461.1192$.

\subsection{Computational Details}

The geometries of cations for complexes $\mathbf{1}$ and $\mathbf{2}$ were optimized using DFT calculations at the B3LYP [53,54] level of theory (20\% Hartree-Fock). Phenyl substituents of the btzpy ligand were simplified to methyl groups to reduce computational cost. The Stuttgart-Dresden relativistic small core effective pseuopotential and basis set was used for osmium [55] and 6-311G* basis sets used for all other atoms [56]. Optimised minima were confirmed through vibrational frequency calculations. TDDFT calculations were carried out at the optimized ground state geometries to compute the vertical excitation energies (lowest 30 singlet and 10 triplet roots) and hence the simulated optical absorption spectra. The $\mathrm{T}_{1}$ states were also optimized and the spin density calculated and plotted. All calculations were carried out using the NWChem 6.6 software package [57] with geometries, molecular orbital surfaces and spin densities viewed and plotted using the ECCE graphical user interface.

\subsection{Cell Culture}

Both HeLa (human cervical cancer) and U2OS (human bone osteosarcoma) cell lines were purchased from American Type Culture Collection-LGC partnership (Teddington, UK) and used within 20 passages of purchase. Cells were cultured in Dulbecco's modified Eagles Medium (DMEM) (Lonza, Cambridge, UK) with 10\% fetal calf serum (FCS) (Lonza, Cambridge, UK) and incubated at $37^{\circ} \mathrm{C}$ under $5 \% \mathrm{CO}_{2}$. Both cell lines were routinely checked for mycoplasma infection. Complex $\mathbf{1}^{\mathrm{Cl}}$ was stored as a stock solution at $10 \mathrm{mM}$ in DMSO.

\subsection{Luminescence Imaging and Colocalisation Studies}

Cover glasses $(22 \times 22 \mathrm{~mm})$ were sterilised (industrial methylated spirits, IMS) and placed flat in 6-well plates. Cells were seeded at a density of $\sim 1 \times 10^{5}$ cells per well and allowed to adhere overnight in culture media. Complex $\mathbf{1}^{\mathrm{Cl}}(1 \mu \mathrm{M})$ was added and incubated for $4 \mathrm{~h}$, for co-localisation studies MitoView ${ }^{\mathrm{TM}} 633$ (Biotium) was added for the final $15 \mathrm{~min}$, prior to cells being washed 3 times in PBS and fixed in $4 \%$ paraformaldehyde solution in PBS at $4{ }^{\circ} \mathrm{C}$ for $20 \mathrm{~min}$. Following a further wash $(P B S \times 3)$ the coverslips were mounted to microscope slides (IMMU-MOUNT ${ }^{\mathrm{TM}}$, Life Technologies Ltd., Paisley, UK). The slides were imaged by confocal microscopy (Nikon A1 confocal) using a $60 \times 1$ lens (CFI Plan Apochromat VC $60 \times$ oil, NA 1.4). An argon laser (405 nm and $561 \mathrm{~nm}$ ) was used to excite complex $1^{\mathrm{Cl}}$ and a diode laser $(642 \mathrm{~nm})$ was used to excite MitoView ${ }^{\mathrm{TM}}$ 633. Colocalisation indices were calculated using the open source imaging software Fiji (based on ImageJ) and the coloc 2 colocalisation tool. The threshold regression chosen was Bisection.

\subsection{Cell Viability Assay-MTT}

96-well plates were seeded with HeLa cells at 1000/well and incubated overnight. Wells were treated with $0.1-100 \mu \mathrm{M}$ complex $1^{\mathrm{Cl}}$ or DMSO control and incubated for $4 \mathrm{~h}$ before replacing with fresh media. After 5 days further growth, $25 \mu \mathrm{L}$ of $3 \mathrm{mg} \mathrm{cm}^{-3}$ thiazoyl blue (MTT) solution was added to each well. Following incubation for $3 \mathrm{~h}$ the solution was removed from each well and $250 \mu \mathrm{L} /$ well DMSO added ensuring mixing of crystals. Optical density of wells at $540 \mathrm{~nm}$ was recorded on a plate reader (Multiskan fc, Thermo Fisher Scientific, Warrington, UK).

\subsection{Clonogenic Survival}

Six-well plates were seeded with HeLa cells at 400 cells/well and incubated overnight. Wells were treated with DMSO, $50 \mu \mathrm{M}$ or $100 \mu \mathrm{M}$ complex $\mathbf{1}^{\mathrm{Cl}}$ for $4 \mathrm{~h}$ before replacing with fresh media. Plates were 
incubated for 8-10 days to form colonies before staining with $4 \%$ methylene blue in $70 \%$ methanol and counting. Each colony was considered to represent a single surviving cell and survival fraction calculated for each condition compared to DMSO control.

Supplementary Materials: The following are available online at www.mdpi.com/1420-3049/21/10/1382/s1, Figure S1: ${ }^{1} \mathrm{H}-\mathrm{NMR}$ spectrum of $\mathbf{1}\left(\mathrm{CD}_{3} \mathrm{CN}\right)$, Figure S2: ${ }^{13} \mathrm{C}-\mathrm{NMR}$ spectrum of $\mathbf{1}\left(\mathrm{CD}_{3} \mathrm{CN}\right)$, Figure S3: ESI mass spectrum of 1, Figure S4: ${ }^{1} \mathrm{H}-\mathrm{NMR}$ spectrum of $\mathbf{1}^{\mathrm{Cl}}\left(d_{6}\right.$-DMSO), Figure S5: ${ }^{13} \mathrm{C}-\mathrm{NMR}$ spectrum of $\mathbf{1}^{\mathrm{Cl}}\left(d_{6}-\mathrm{DMSO}\right)$, Figure S6: ESI mass spectrum of $\mathbf{1}^{\mathrm{Cl}}, \mathrm{XYZ}$ coordinates for the optimized geometries of the ground and lowest lying triplet states of 1, Figure S7: Time-dependent DFT UV-visible absorption spectrum of 1, Table S1: Summarised time-dependent DFT data for 1.

Acknowledgments: The authors thank the State of Libya (SAEO), University of Huddersfield (PAS), Yorkshire Cancer Research, Cancer Research UK, BBSRC, The Wellcome Trust, EPSRC KTA and University of Sheffield (LKM, HEB \& JAW) for supporting this work. Microscopy was performed on equipment purchased on the following grants: Welcome Trust grant WT093134AIA and MRC SHIMA award MR/K015753/1. As a member of the UK Materials Chemistry Consortium PIPE acknowledges the EPSRC (EP/L000202) and the UK HPC national resource, Archer, as well as the University of Huddersfield High Performance Computing Research Group for computational facilities utilized in this work.

Author Contributions: SAEO carried out the majority of experimental synthetic and spectroscopic work. PAS carried out additional experimental work and acted as co-supervisor for SAEO. LKM carried out cellular uptake and imaging studies under the supervision of HEB and JAW. Principal investigator PIPE carried out computational calculations and was the main manuscript author, and PAS, HEB, LKM and JAW assisted in writing the manuscript.

Conflicts of Interest: The authors declare no conflict of interest.

\section{References}

1. Baba, A.I.; Shaw, J.R.; Simon, J.A.; Thummel, R.P.; Schmehl, R.H. The photophysical behavior of $\mathrm{d}^{6}$ complexes having nearly isoenergetic MLCT and ligand localized excited states. Coord. Chem. Rev. 1998, 171, 43-59. [CrossRef]

2. Balzani, V.; Ceroni, P.; Juris, A. Photochemistry and Photophysics: Concepts, Research, Applications; Wiley-VCH: Weinheim, Germany, 2014.

3. Happ, B.; Winter, A.; Hager, M.D.; Schubert, U.S. Photogenerated avenues in macromolecules containing $\operatorname{Re}(\mathrm{I}), \mathrm{Ru}(\mathrm{II}), \mathrm{Os}(\mathrm{II})$, and $\mathrm{Ir}(\mathrm{III})$ metal complexes of pyridine-based ligands. Chem. Soc. Rev. 2012, 41, 2222-2255. [CrossRef] [PubMed]

4. Kumaresan, D.; Shankar, K.; Vaidya, S.; Schmehl, R.H. Photochemistry and Photophysics of Coordination Compounds: Osmium. In Photochemistry and Photophysics of Coordination Compounds; Balzani, V., Campagna, S., Eds.; Springer: Berlin, Germany, 2007; Volume 281, pp. 101-142.

5. Costa, R.D.; Ortí, E.; Bolink, H.J. Recent advances in light-emitting electrochemical cells. Pure Appl. Chem. 2011, 83, 2115-2128. [CrossRef]

6. Hagfeldt, A.; Boschloo, G.; Sun, L.; Kloo, L.; Pettersson, H. Dye-sensitized solar cells. Chem. Rev. 2010, 110, 6595-6663. [CrossRef] [PubMed]

7. Crowley, J.D.; McMorran, D.A. “Click-triazole” coordination chemistry: Exploiting 1,4-disubstituted1,2,3-triazoles as ligands. In Click Triazoles; Košmrljc, J., Ed.; Springer: Berlin, Germany, 2012; Volume 28, pp. 31-83.

8. Elliott, P.I.P. Organometallic complexes with 1,2,3-triazole-derived ligands. In Organometallic Chemistry; RSC Publishing: Cambridge, UK, 2014; Volume 39, p. 1.

9. Kumar, S.V.; Scottwell, S.O.; Waugh, E.; McAdam, C.J.; Hanton, L.R.; Brooks, H.J.L.; Crowley, J.D. Antimicrobial Properties of Tris(homoleptic) Ruthenium(II) 2-Pyridyl-1,2,3-triazole "Click" Complexes against Pathogenic Bacteria, Including Methicillin-Resistant Staphylococcus aureus (MRSA). Inorg. Chem. 2016, 55, 9767-9777. [CrossRef] [PubMed]

10. Preston, D.; Barnsley, J.E.; Gordon, K.C.; Crowley, J.D. Controlled Formation of Heteroleptic $\left[\mathrm{Pd} 2(\mathrm{La})_{2}(\mathrm{Lb})_{2}\right]^{4+}$ Cages. J. Am. Chem. Soc. 2016, 138, 10578-10585. [CrossRef] [PubMed]

11. Beyer, B.; Ulbricht, C.; Escudero, D.; Friebe, C.; Winter, A.; Gonzalez, L.; Schubert, U.S. Phenyl-1H-[1,2,3] triazoles as New Cyclometalating Ligands for Iridium(III) Complexes. Organometallics 2009, $28,5478$. [CrossRef] 
12. Happ, B.; Escudero, D.; Hager, M.D.; Friebe, C.; Winter, A.; Goerls, H.; Altuntas, E.; Gonzalez, L.; Schubert, U.S. N-Heterocyclic Donor- and Acceptor-Type Ligands Based on 2-(1H-1,2,3 Triazol-4-yl)pyridines and Their Ruthenium(II) Complexes. J. Org. Chem. 2010, 75, 4025-4038. [CrossRef] [PubMed]

13. Happ, B.; Friebe, C.; Winter, A.; Hager, M.D.; Hoogenboom, R.; Schubert, U.S. 2-(1H-1,2,3-Triazol-4-yl)Pyridine Ligands as Alternatives to 2,2'-Bipyridines in Ruthenium(II) Complexes. Chem. Asian J. 2009, 4, 154-163. [CrossRef] [PubMed]

14. Ladouceur, S.; Fortin, D.; Zysman-Colman, E. Enhanced Luminescent Iridium(III) Complexes Bearing Aryltriazole Cyclometallated Ligands. Inorg. Chem. 2011, 50, 11514-11526. [CrossRef] [PubMed]

15. Ladouceur, S.; Zysman-Colman, E. A Comprehensive Survey of Cationic Iridium(III) Complexes Bearing Nontraditional Ligand Chelation Motifs. Eur. J. Inorg. Chem. 2013, 2985-3007. [CrossRef]

16. Mydlak, M.; Bizzarri, C.; Hartmann, D.; Sarfert, W.; Schmid, G.; de Cola, L. Positively Charged Iridium(III) Triazole Derivatives as Blue Emitters for Light-Emitting Electrochemical Cells. Adv. Funct. Mater. 2010, 20, 1812-1820. [CrossRef]

17. Obata, M.; Kitamura, A.; Mori, A.; Kameyama, C.; Czaplewska, J.A.; Tanaka, R.; Kinoshita, I.; Kusumoto, T.; Hashimoto, H.; Harada, M.; et al. Syntheses, structural characterization and photophysical properties of 4-(2-pyridyl)-1,2,3-triazole rhenium(I) complexes. Dalton Trans. 2008, 25, 3292-3300. [CrossRef] [PubMed]

18. Orselli, E.; Albuquerque, R.Q.; Fransen, P.M.; Froehlich, R.; Janssen, H.M.; de Cola, L. 1,2,3-Triazolyl-pyridine derivatives as chelating ligands for blue iridium(III) complexes. Photophysics and electroluminescent devices. J. Mater. Chem. 2008, 18, 4579-4590. [CrossRef]

19. Ross, D.A.W.; Scattergood, P.A.; Babaei, A.; Pertegás, A.; Bolink, H.J.; Elliott, P.I.P. Luminescent osmium(II) bi-1,2,3-triazol-4-yl complexes: Photophysical characterisation and application in light-emitting electrochemical cells. Dalton Trans. 2016, 45, 7748-7757. [CrossRef] [PubMed]

20. Schulze, B.; Friebe, C.; Hager, M.D.; Winter, A.; Hoogenboom, R.; Goerls, H.; Schubert, U.S. $2,2^{\prime}: 6^{\prime}, 2^{\prime \prime}$-Terpyridine meets 2,6-bis(1H-1,2,3-triazol-4-yl)pyridine: Tuning the electro-optical properties of ruthenium(II) complexes. Dalton Trans. 2009, 5, 787-794. [CrossRef] [PubMed]

21. Swanick, K.N.; Ladouceur, S.; Zysman-Colman, E.; Ding, Z. Bright electrochemiluminescence of iridium(III) complexes. Chem. Commun. 2012, 48, 3179-3181. [CrossRef] [PubMed]

22. Swanick, K.N.; Ladouceur, S.; Zysman-Colman, E.; Ding, Z. Self-Enhanced Electrochemiluminescence of an Iridium(III) Complex: Mechanistic Insight. Angew. Chem. Int. Ed. 2012, 51, 11079-11082. [CrossRef] [PubMed]

23. Uppal, B.S.; Booth, R.K.; Ali, N.; Lockwood, C.; Rice, C.R.; Elliott, P.I.P. Synthesis and characterisation of luminescent rhenium tricarbonyl complexes with axially coordinated 1,2,3-triazole ligands. Dalton Trans. 2011, 40, 7610-7616. [CrossRef] [PubMed]

24. Welby, C.E.; Gilmartin, L.; Marriott, R.R.; Zahid, A.; Rice, C.R.; Gibson, E.A.; Elliott, P.I.P. Luminescent biscyclometalated arylpyridine iridium(III) complexes with 4,4'-bi-1,2,3-triazolyl ancillary ligands. Dalton Trans. 2013, 42, 13527-13536. [CrossRef] [PubMed]

25. Zanarini, S.; Felici, M.; Valenti, G.; Marcaccio, M.; Prodi, L.; Bonacchi, S.; Contreras-Carballada, P.; Williams, R.M.; Feiters, M.C.; Nolte, R.J.M.; et al. Green and Blue Electrochemically Generated Chemiluminescence from Click Chemistry-Customizable Iridium Complexes. Chem. Eur. J. 2011, 17, 4640-4647. [CrossRef] [PubMed]

26. Baggaley, E.; Weinstein, J.A.; Williams, J.A.G. Lighting the way to see inside the live cell with luminescent transition metal complexes. Coord. Chem. Rev. 2012, 256, 1762-1785. [CrossRef]

27. Holmlin, R.E.; Yao, J.A.; Barton, J.K. Dipyridophenazine complexes of Os(II) as red-emitting DNA probes: Synthesis, characterization, and photophysical properties. Inorg. Chem. 1999, 38, 174-189. [CrossRef]

28. Lo, K.K.W. Luminescent Rhenium(I) and Iridium(III) Polypyridine complexes as biological probes, imaging reagents, and photocytotoxic agents. Acc. Chem. Res. 2015, 48, 2985-2995. [CrossRef] [PubMed]

29. Baggaley, E.; Botchway, S.W.; Haycock, J.W.; Morris, H.; Sazanovich, I.V.; Williams, J.A.G.; Weinstein, J.A. Long-lived metal complexes open up microsecond lifetime imaging microscopy under multiphoton excitation: From FLIM to PLIM and beyond. Chem. Sci. 2014, 5, 879-886. [CrossRef]

30. Baggaley, E.; Weinstein, J.A.; Williams, J.A.G. Time-resolved emission imaging microscopy using phosphorescent metal complexes: Taking FLIM and PLIM to new lengths. In Structure and Bonding; Lo, K.K.-W., Ed.; Springer: Berlin, Germany, 2015; Volume 165, pp. 205-256. 
31. Jahn, K.; Buschmann, V.; Hille, C. Simultaneous fluorescence and phosphorescence lifetime imaging microscopy in living cells. Sci. Rep. 2015, 5, 14334. [CrossRef] [PubMed]

32. Ito, A.; Knight, T.E.; Stewart, D.J.; Brennaman, M.K.; Meyer, T.J. Rigid medium effects on photophysical properties of MLCT excited states of polypyridyl Os(II) complexes in polymerized poly(ethylene glycol)dimethacrylate monoliths. J. Phys. Chem. A 2014, 118, 10326-10332. [CrossRef] [PubMed]

33. Kober, E.M.; Meyer, T.J. Concerning the absorption spectra of the ions $\mathrm{M}(\mathrm{bpy})_{3}{ }^{2+}(\mathrm{M}=\mathrm{Fe}, \mathrm{Ru}, \mathrm{Os}$; bpy = 2,2-bipyridine). Inorg. Chem. 1982, 21, 3967-3977. [CrossRef]

34. Lumpkin, R.S.; Kober, E.M.; Worl, L.A.; Murtaza, Z.; Meyer, T.J. Metal-to-ligand charge-transfer (MLCT) photochemistry. Experimental evidence for the participation of a higher lying MLCT state in polypyridyl complexes of ruthenium(II) and osmium(II). J. Phys. Chem. 1990, 94, 239-243. [CrossRef]

35. Scattergood, P.A.; Ross, D.A.W.; Rice, C.R.; Elliott, P.I.P. Labilizing the photoinert: Extraordinarily facile photochemical ligand ejection in an $\left[\mathrm{Os}\left(\mathrm{N}^{\wedge} \mathrm{N}\right)_{3}\right]^{2+}$ complex. Angew. Chem. Int. Ed. 2016, 55, 10697-10701. [CrossRef] [PubMed]

36. Stacey, O.J.; Pope, S.J.A. New avenues in the design and potential application of metal complexes for photodynamic therapy. RSC Adv. 2013, 3, 25550-25564. [CrossRef]

37. Allampally, N.K.; Daniliuc, C.G.; Strassert, C.A.; de Cola, L. Tuning the structural and photophysical properties of cationic $\mathrm{Pt}(\mathrm{II})$ complexes bearing neutral bis(triazolyl)pyridine ligands. Inorg. Chem. 2015, 54, 1588-1596. [CrossRef] [PubMed]

38. Crowley, J.D.; Bandeen, P.H.; Hanton, L.R. A one pot multi-component CuAAC "click" approach to bidentate and tridentate pyridyl-1,2,3-triazole ligands: Synthesis, X-ray structures and copper(II) and silver(I) complexes. Polyhedron 2010, 29, 70-83. [CrossRef]

39. Constable, E.C.; Thompson, A.M.W.C. Pendant-functionalised ligands for metallosupramolecular assemblies; ruthenium(II) and osmium(II) complexes of $4^{\prime}$-(4-pyridyl)-2,2' $: 6^{\prime}, 2^{\prime \prime}$-terpyridine. J. Chem. Soc. Dalton Trans. 1994, 9, 1409-1418. [CrossRef]

40. Fortage, J.; Dupeyre, G.; Tuyèras, F.; Marvaud, V.; Ochsenbein, P.; Ciofini, I.; Hromadová, M.; Pospísil, L.; Arrigo, A.; Trovato, E.; et al. Molecular dyads of ruthenium(II)- or osmium(II)-bis(terpyridine) chromophores and expanded pyridinium acceptors: Equilibration between MLCT and charge-separated excited states. Inorg. Chem. 2013, 52, 11944-11955. [CrossRef] [PubMed]

41. Shao, J.Y.; Zhong, Y.W. Monometallic osmium(II) complexes with bis(N -methylbenzimidazolyl)benzene or -pyridine: A comparison study with ruthenium(II) analogues. Inorg. Chem. 2013, 52, 6464-6472. [CrossRef] [PubMed]

42. Li, Y.; Huffman, J.C.; Flood, A.H. Can terdentate 2,6-bis(1,2,3-triazol-4-yl)pyridines form stable coordination compounds? Chem. Commun. 2007, 26, 2692-2694. [CrossRef] [PubMed]

43. Wadman, S.H.; Lutz, M.; Tooke, D.M.; Spek, A.L.; Hartl, F.; Havenith, R.W.A.; van Klink, G.P.M.; van Koten, G. Consequences of N, C, N'- and C, N, N'-coordination modes on electronic and photophysical properties of cyclometalated aryl ruthenium(II) complexes. Inorg. Chem. 2009, 48, 1887-1900. [CrossRef] [PubMed]

44. Yang, W.W.; Zhong, Y.W.; Yoshikawa, S.; Shao, J.Y.; Masaoka, S.; Sakai, K.; Yao, J.; Haga, M.A. Tuning of redox potentials by introducing a cyclometalated bond to bis-tridentate ruthenium(II) complexes bearing bis(N -methylbenzimidazolyl) benzene or -pyridine ligands. Inorg. Chem. 2012, 51, 890-899. [CrossRef] [PubMed]

45. Suzuki, K.; Kobayashi, A.; Kaneko, S.; Takehira, K.; Yoshihara, T.; Ishida, H.; Shiina, Y.; Oishi, S.; Tobita, S. Reevaluation of absolute luminescence quantum yields of standard solutions using a spectrometer with an integrating sphere and a back-thinned CCD detector. Phys. Chem. Chem. Phys. 2009, 11, 9850-9860. [CrossRef] [PubMed]

46. Sauvage, J.P.; Collin, J.P.; Chambron, J.C.; Guillerez, S.; Coudret, C.; Balzani, V.; Barigelletti, F.; de Cola, L.; Flamigni, L. Ruthenium(II) and osmium(II) bis(terpyridine) complexes in covalently-linked multicomponent systems: Synthesis, electrochemical behavior, absorption spectra, and photochemical and photophysical properties. Chem. Rev. 1994, 94, 993-1019. [CrossRef] 
47. Abrahamsson, M.; Wolpher, H.; Johansson, O.; Larsson, J.; Kritikos, M.; Eriksson, L.; Norrby, P.O.; Bergquist, J.; Sun, L.; Åkermark, B.; et al. A new strategy for the improvement of photophysical properties in ruthenium(II) polypyridyl complexes. Synthesis and photophysical and electrochemical characterization of six mononuclear ruthenium(II) bisterpyridine-type complexes. Inorg. Chem. 2005, 44, 3215-3225. [CrossRef] [PubMed]

48. Kreitner, C.; Heinze, K. Excited state decay of cyclometalated polypyridine ruthenium complexes: Insight from theory and experiment. Dalton Trans. 2016, 45, 13631-13647. [CrossRef] [PubMed]

49. Zhang, X.; Pápai, M.; Møller, K.B.; Zhang, J.; Canton, S.E. Characterizing the solvated structure of photoexcited $\left[\mathrm{Os}(\text { terpy })_{2}\right]^{2+}$ with X-ray transient absorption spectroscopy and DFT calculations. Molecules 2016, 21, 235-243. [CrossRef] [PubMed]

50. Scattergood, P.A.; Delor, M.; Sazanovich, I.V.; Bouganov, O.V.; Tikhomirov, S.A.; Stasheuski, A.S.; Parker, A.W.; Greetham, G.M.; Towrie, M.; Davies, E.S.; et al. Electron transfer dynamics and excited state branching in a charge-transfer platinum(II) donor-bridge-acceptor assembly. Dalton Trans. 2014, 43, 17677-17693. [CrossRef] [PubMed]

51. Abrahamse, H.; Hamblin, M.R. New photosensitizers for photodynamic therapy. Biochem. J. 2016, 473, 347-364. [CrossRef] [PubMed]

52. Hamann, T.W.; Gstrein, F.; Brunschwig, B.S.; Lewis, N.S. Measurement of the free-energy dependence of interfacial charge-transfer rate constants using $\mathrm{ZnO} / \mathrm{H}_{2} \mathrm{O}$ semiconductor/liquid contacts. J. Am. Chem. Soc. 2005, 127, 7815-7824. [CrossRef] [PubMed]

53. Becke, A.D. Density-functional thermochemistry. III. The role of exact exchange. J. Chem. Phys. 1993, 98, 5648-5652. [CrossRef]

54. Stephens, P.J.; Devlin, F.J.; Chabalowski, C.F.; Frisch, M.J. Ab Initio calculation of vibrational absorption and circular dichroism spectra using density functional force fields. J. Phys. Chem. 1994, 98, 11623-11627. [CrossRef]

55. Andrae, D.; Häußermann, U.; Dolg, M.; Stoll, H.; Preuß, H. Energy-adjusted ab initio pseudopotentials for the second and third row transition elements. Theor. Chim. Acta 1990, 77, 123-141. [CrossRef]

56. Krishnan, R.; Binkley, J.S.; Seeger, R.; Pople, J.A. Self-consistent molecular orbital methods. XX. A basis set for correlated wave functions. J. Chem. Phys. 1980, 72, 650-654. [CrossRef]

57. Valiev, M.; Bylaska, E.J.; Govind, N.; Kowalski, K.; Straatsma, T.P.; van Dam, H.J.J.; Wang, D.; Nieplocha, J.; Apra, E.; Windus, T.L.; et al. NWChem: A comprehensive and scalable open-source solution for large scale molecular simulations. Comp. Phys. Commun. 2010, 181, 1477-1489. [CrossRef]

Sample Availability: Samples of the compounds are not available.

(C) 2016 by the authors; licensee MDPI, Basel, Switzerland. This article is an open access article distributed under the terms and conditions of the Creative Commons Attribution (CC-BY) license (http:/ / creativecommons.org/licenses/by/4.0/). 